\title{
Cooperative Game on Economic Management of Air Environment
}

\author{
Weihua $\mathrm{Du}$ \\ The School of Economics, Shanghai University of Finance and Economics \\ 777 Guoding RD, Shanghai 200433, China
}

Tel: 86-21-6590-3687Ｅ-mail: duweihua@mail.shufe.edu.cn

Thanks to financial support of the third construction project in the "211 Project" of Shanghai University of Finance and Economics. The author takes sole responsibility for the consequence of this article.

\begin{abstract}
Compound air pollution is becoming one of three major problems of urban ecological security in China which is experiencing a rapid growth. This paper is to establish optional points of Decision-making model and 10 portions of force model from two aspects on objective opportunity and subjective will, and logically and historically analyze the game theory of regional joint prevention and joint control in solving this problem, so as to provide theoretical guidance for regional cooperation and management decisions.
\end{abstract}

Keywords: Air environment, Economic management, Cooperative game

\section{Introduction}

According to scientific calculations, an adult breathes about 20 thousand times per day, and inbreathe $15-20 \mathrm{~m}^{3}$ air, which approximately equals to 10 times of food and water required per day if converted into kilograms. Therefore, air pollution on human health is not only deep but also direct. However, along with technological innovation and rapid development of cities, for many cities in the world, especially economically developed regions and new emerging economies like China and India, due to the rapid industrial development in a relatively short period, increased living pollution brought by population density, and increased car exhaust pollution, the overall air environment steps into a compound stage with coexistence of multiple pollutants and superposition of multiple sources of pollution. The compound air pollution is becoming one of three major problems of the cities which are experiencing a rapid growth, especially China's urban ecological security.

\section{Optional points of Decision-making model}

If in a closed and homogenous air environment system, only considering the effect of human activities on air environment resource, i.e. assuming meet the following conditions:

Assumption 1: the system is not influenced by weather factors like whether force and vertical distribution of air;

Assumption 2: the system is not influenced by underlying surface factors like complex topography;

Assumption 2: the system is not influenced by other factors like season.

We design a comprehensive index to quantitatively describe the extent of air pollution. Thus according to air environment during the course of human history, we can obtain the air pollution intensity curve model shown as Figure 1. We can find 4 characteristics of the model in the figure:

Characteristic 1: The slop of pollution curve is minimum before $18^{\text {th }}$ Century, and the curve gently goes up. It physically means air environment problem is not obvious. Characteristic 2 : From early $18^{\text {th }}$ Century to mid- $20^{\text {th }}$ Century, the curve rapidly rises with larger slope. It physically means air environment is seriously deteriorated with outstanding problems during this period. Characteristic 3 : In late $20^{\text {th }}$ Century, the slope of curve goes down, but not obviously. The curve rises still greatly. It physically means the air pollution becomes better, but without much success, and with a greater absolute pollution concentration (although the slope of the curve decreases, but still rising). Characteristic 4 : After point $\mathrm{W}$ of late $20^{\text {th }}$ Century and early $21^{\text {st }}$ Century, we separate four dot curves by A, B, C and D, according to different level of air pollution. Line A goes through human survival line, Line B rises to somewhere between survival crisis line and survival line, Line $\mathrm{C}$ reaches just the crisis line, and Line D only enters the place between general victimization line and survival crisis line. It physically means, point $\mathrm{W}$ represents human current historical position, and $\mathrm{A}, \mathrm{B}, \mathrm{C}$ and $\mathrm{D}$ are the future air environment human maybe live in.

Economic meaning of the model: Before $18^{\text {th }}$ Century, the relationship between human and air environment was in the original state of coordination or low level and basic coordination. So the damage to air environment was small, and air environment problems were not enough to affect human's survival and development. Thus as far 
as the people at that time are concerned, it is not a problem. The early $18^{\text {th }}$ Century to the mid- $20^{\text {th }}$ Century was the industrialization era at the expense of environment, simply pursuing economic efficiency. The air environment was increasingly deteriorating, and "public nuisance" occurs frequently. The relationship between human and air environment has developed from uncoordinated to extreme uncoordinated. The air environment problem is very serious. In the late $20^{\text {th }}$ Century, people began to attach importance to air environment and took a series of positive and effective measures, which results in lower intensity of air environment deterioration. However, due to some reasons like inadequate efforts, the absolute value of pollution intensity was still rising, and air environment continues to deteriorate. Point $\mathrm{W}$ is the core point of the turn of the century. One hand, according to previous human's efforts to control air pollution, we can lead to possible trajectory of different intensity from point $\mathrm{W}$. On the other hand, point $\mathrm{W}$ emphasizes currently human is at the choice point of life and death. As this choice point is systematically determined by many objective conditions, such as time, air pollution base, local victim line of human, general victim line, survival hope line and asphyxia line. So as for modern people with four options of A, B, C and D, this good opportunity is not only an objective fortune, but also the challenge to life breath security on the earth.

\section{3. "10 portions of force" model}

We define the real efforts made by modern mankind to successfully take international and national objective opportunities to completely solve the air environment problem as opportunity force, represented as $\mathrm{F}$. In the established coordinate system, horizontal coordinates represent the subjective will force, $\mathrm{W}$, to accept challenge and take opportunity, and vertical coordinates represent objective ability, S.

Assumption 1: The opportunity force of absolutely taking opportunities to completely solve air environment is 10 units or 10 portions of force, represented by vector OF. That is to say, only when modern mankind pay 10 portions of efforts, can they absolutely and successfully take opportunities to completely solve air environment problems which are threatening human life system.

Assumption 2: The subjective will force (W) and objective ability (S) both can be vectors, and the OF vector can be decomposed into two sub-vectors perpendicular to each other, i.e. the horizontal subjective will force OW and vertical objective ability OS.

Therefore, the vector made by any intersection in the equivalently divided $10 \times 10$ grid from coordinate origin $O$ to OWFS respectively represents a kind of effective combination of opportunity force of "subjective will force" and "objective ability". Moreover, each grid represents a corresponding portion of force. For example, vector OA means the effective combination of opportunity force of 10 portions of objective ability and 3 portions of subjective will force, and vector OB means that of 3 portions of objective ability and 10 portions of subjective will force.

\section{Roommate Game}

Definition 1: If there are several people living in the same room, they call each other "roommate".

Definition 2: "A real and effective cooperation" refers to the willingness to cooperate along with specific cooperative behavior, and effective result of this behavior within the time allowed.

Definition 3: "Real cooperation" refers to the willingness to cooperate along with specific cooperative behavior, but uncertain effect of this behavior within the time allowed.

Definition 4: "Non-real cooperation" refers to the willingness to cooperate without specific cooperative behavior.

Definition 5: "noncooperation" means no willingness to cooperate at all. Thus, we can design a "roommate game", so as to illustrate the key to break "bottleneck" is the national and international cooperative power.

According to current air pollution and nonequilibrium economic strength, we can imagine the earth as a large room, where the rich and the poor live (The rich and the poor are roommates. The rooftop is $12-35 \mathrm{~km}$ high ozone shield.). The thinning ozone layer can be abstracted for "hole" of the rooftop of the room where they live. Referring to " 10 portions of force" model, we assume that, (1) the value of the opportunity force, OF (the length of line OF), which can completely solve "hole" problem, is within $[10, \infty]$; (2) the value of the opportunity force, $\mathrm{OF}$, which can not completely solve "hole" problem, but can effectively deal with it, is within $[8,10]$. We say the coordinates of four points, R, K, T and F, are respectively $(8 \cos 45,10),(8 \sin 45,8 \cos 45),(10,8 \sin 45)$ and $(10$, 10 ), so the square RFTK is the effectively dealing area to "hole" problem (the black box in Figure 2).

Considering that the poor and the rich have to patch the roof's hole on condition of maintaining their survival and development, we assume they will spend at most $20 \%$ of their own money on this issue, i.e. their subjective will is within $[0,2]$. Furthermore, the rich and the poor can not completely solve the "hole" problem separately, 
and the objective ability of the rich is stronger than that of the poor. So we assume the objective ability of the rich is within $[0,6]$, that of the poor is within $[0,3]$. By the " 10 portions of force" model, we can obtain the opportunity value $|\mathrm{OF}|$ by the Pythagorean Theorem to get the opportunity value interval of both parties. According to the interval estimation of probability theory, after screening and positioning, we obtain the set of opportunity values of both parties, as Table 1 . Therefore, in this game, there are two parties, i.e. the rich and the poor. Their respective strategy space is the set (real and effective cooperation, real cooperation, non-real cooperation and noncooperation). The payoff in the game is the opportunity values of each party. Furthermore, we assume the rich and the poor can make strategy simultaneously, or can be regarded as the same time, the payoff matrix is shown as Table 2 .

Game analysis: The "roommate game" is essentially a static and variable game. If the two parties of the game both consider "short-term individual behavior rational", i.e. maximizing short-term interest as the only goal, the rich and the poor should both choose non-cooperation. Then neither of them contributes their strength at all. However, the result can only be gradually expanded hole in the roof, leading to serious destruction of life support system and being unable to survive of the poor and the rich. If the two parties of the game both consider "long-term individual behavior rational", i.e. maximizing long-term interest as the only goal, the rich and the poor should both choose real and effective cooperation. Then the total opportunity value is maximized (see Table 2 ), which is $3.6+6.3=9.9$, belonging to $[8,10]$, i.e. effective handling area of the "hole" of opportunity value. If one party of the game considers "long-term individual behavior rational", while the other one consider "short-term individual behavior rational", then in order to effectively handle "hole" problem, they should choose real cooperation or better strategies. According to the game payoff matrix, the total opportunity value of real cooperation and real and effective cooperation belongs to the effective handling value area $[8,10]$. That is to say, only the strategies of $2 \times 2$ sub-matrix of upper left corner in total force value matrix (Table 2 ) of the game payoff are possible to deal with "hole" problem effectively. If the rich always emphasize on "equal" contribution as the poor, their most possible contribution is 4.1 units of force, as the power of the poor is limited within 3.6 units (see Table 1). In other words, to repair the "hole" in the roof facing everyone with "equal" contribution, the best result can only be a real and effective cooperation by the poor and a non-real cooperation by the rich (see Table 1), when the total power gain of the game is 7.7 (see Table 2). For $7.7<8$, it doesn't belong to the effective handling area of "hole" problem $[8,10]$. Therefore, the final result of this strategies combination is only the loss of opportunity with life-long pity.

Actually, the problem of air pollution is not limited within a country, so it is very significant to make international environmental cooperation. Fortunately, on this issue the international community has made remarkable achievement, with "Montreal Protocol" as one of the best examples, which probably enable the destructed ozone layer be recovered within half a century.

\section{Conclusion and discussion}

If reviewing the development theories and practices so far from the particular perspective of quantity and quality views of development, we will see the modern traditional development theory of the third world is established on the basis of the single-line evolutionary development concept and "quantitative expansion". The economic growth modes of developed countries don't have universality, which won't produce "trickle effects". The quantitative expansion won't naturally solve economic and social "quality" issues including environment.

If developing countries become to solve life quality issue after experiencing "high mass consumption" stage, most of them, including China, will think about the issue of "pursuit of quality of life" within non-foreseeable future. And before then, the life support system which human depends on is likely to have already been destroyed by vicious development such as population growth and environmental destruction.

Today, the population of developed countries only accounts for $1 / 5$ of the world's population, but they consume $90 \%$ of total world energy. In order to start the mechanical devices in production and life, each American annual consumption is equal to what 500 people exhaust on work. The population of America is less than $6 \%$ of the world's population, but they consume over $1 / 3$ of world's raw materials and energy. Developing countries can't manage that kind of high consumption on the basis of this condition. The particular "history stipulation" of China's objective development condition determines China is on the key optional point of decision-making of development currently (see Figure 1).

So China is planning to cut emission voluntarily. In fact, once starting to improve the quality of life, we will find the improvement of the quality of life and economic development has the condition of synchronization. From the "10 portions of force" model and the roommate game analysis, we can see, the final target of economic development which we emphasize on, quality of life, not only meets the precondition of economic growth, but 
also highlights win-win cooperation, to improve the sound running of the entire economic and social level.

\section{References}

D.C. North. (1994). Economic History Structure and Change. Shanghai People's Publishing House.

Du Weihua. (2004). On "Roommate Game" and global environmental management strategies. Economic and Management.

Grossman G M and Krueger A B. (1995). Economic growth and the environment. Quarterly Journal Economics.110 (2): $353-377$.

Murray CJL and Lopez AD. (1997). Global mortality, disability, and the contribution of risk factors: Global Burden of Disease Study. Lancet.349:1436-1442.

Selden T and Song D. (1994). Environmental quality and development: Is there a Kuznets curve for air pollution emission. Journal of Environmental Economics and Management. 35: 126 - 41.

Zhang Xunhua. (1995). Productivity and Economic Law. Fudan University Press.

Table 1. Payoff matrix of roommate game

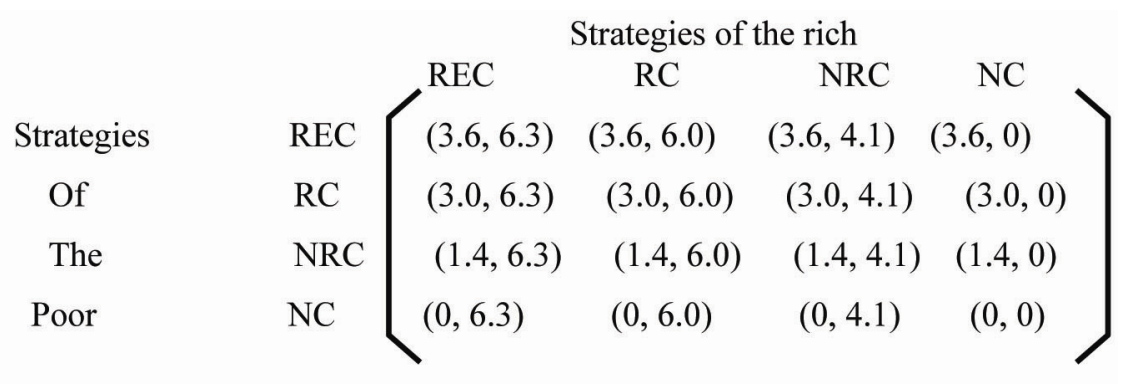

REC--real and effective cooperation;

RC--real cooperation;

NRC--non-real cooperation;

NC: noncooperation

Table 2. Game Payoff matrix of total gains

$\begin{array}{ll}\text { Strategies } & \text { REC } \\ \text { Of } & \text { RC } \\ \text { The } & \text { NRC } \\ \text { Poor } & \text { NC }\end{array} \quad\left[\begin{array}{cccc}\text { REC } & \text { RC } & \text { NRC } & \text { NC } \\ 9.9 & 9.6 \\ 9.3 & 9.0 \\ 7.7 & 7.6 & 7.7 & 3.6 \\ 7.1 & 3.0 \\ 6.3 & 6.0 & 4.5 & 1.4 \\ & & & \end{array}\right]$

REC--real and effective cooperation; 
RC--real cooperation;

NRC--non-real cooperation;

$\mathrm{NC}$ : noncooperation

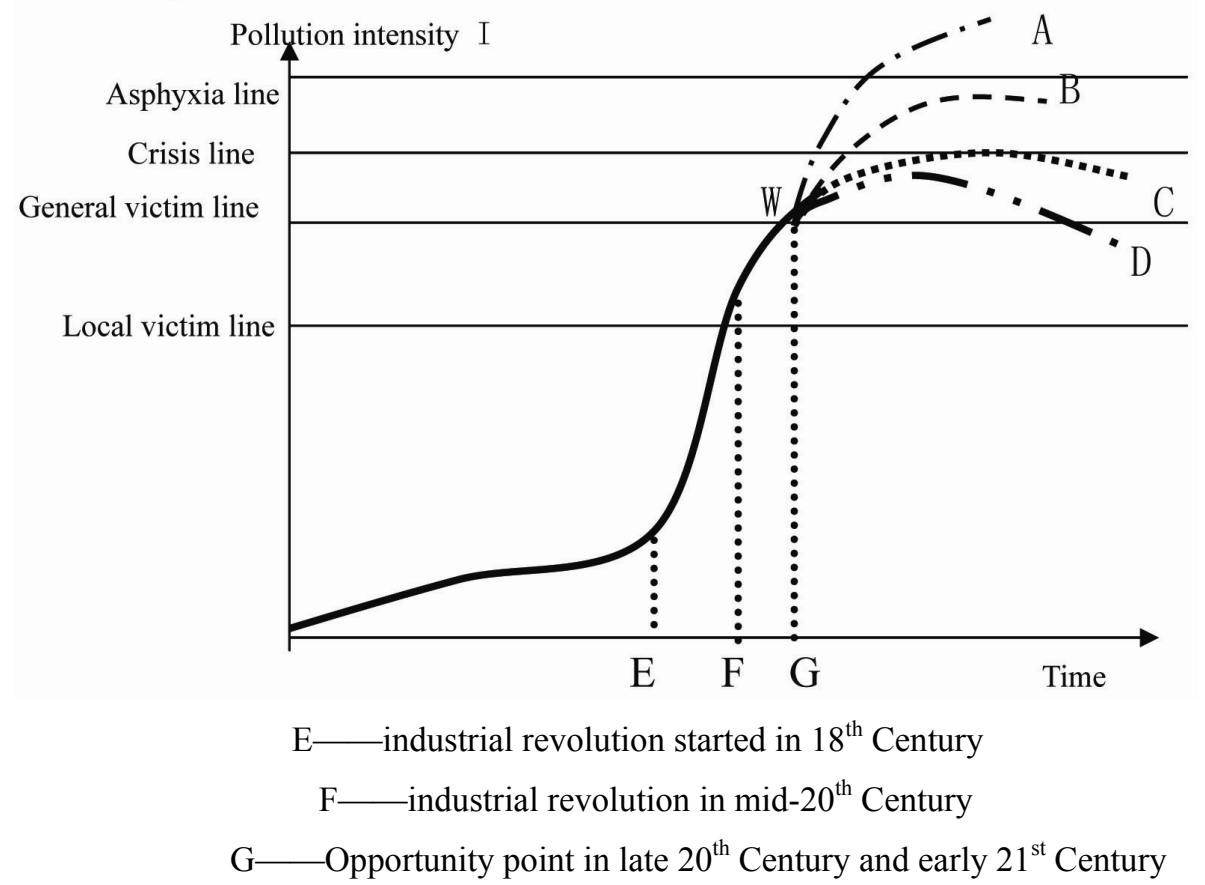

Figure 1. Model of key optional point of decision-making

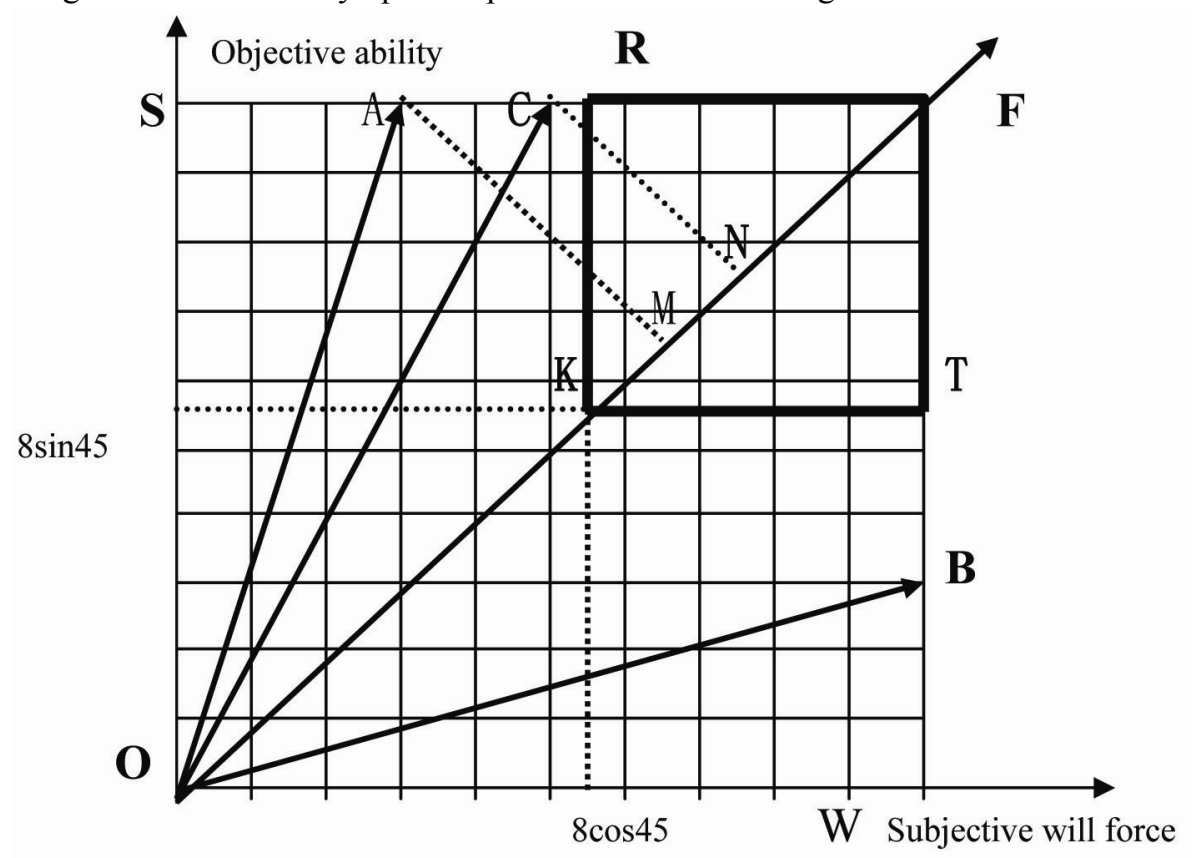

Figure 2. A simple model of"10 portions of force" 